\title{
A State-of-the-Art Conference on Implementing Evidence in Health Care
}

\author{
Reasons and Recommendations
}

In the late summer of 2004, the Veterans Health Administration (VHA) convened an invitational symposium, one in a series of state-of-the-art (SOTA) conferences. VHA's SOTAs are high-level "think tank" sessions with a defined agenda focusing on a specific health care topic. The theme of this SOTA conference was "Implementing the Evidence: Transforming Practices, Systems, and Organizations."

About 100 individuals from across North America, not just from within VHA, gathered for 2 days in the Nation's capital. These were the perceived thought leaders in the implementation sciences, enriched by a few influential "movers" within the largest single health care system in the United States (the VHA). To maximize the yield of the 2 days of SOTA conference brainstorming, VHA commissioned papers to be circulated in draft form before the SOTA, with the intent of priming the pump for discussions organized into specific work groups. This issue of the Journal presents these commissioned papers, revised after the conference, selected and refined through peer review, and augmented by additional manuscripts from SOTA participants and their collaborators who responded to a thematic solicitation.

\section{WHY AN IMPLEMENTATION SOTA?}

The uptake of new findings from clinical research into clinical practice and improved care is a slow, mostly unpredictable, and arduous process. A recent Institute of Medicine report states that "at no time in the history of medicine has the growth in knowledge and technologies been so profound" yet our " ... health care system ... frequently falls short in its ability to translate knowledge into practice."1 Along parallel lines, the most recent National Institutes of Health (NIH) roadmap acknowledges translation as a key issue in medicine, and it has been estimated that it takes on average 17 years for research findings to be fully implemented into clinical practice. ${ }^{2}$ Hence, the urgent need for more rapid implementation. But how to accomplish this?

In his overview of this special issue of the Journal, Fihn expands on the above paragraph and summarizes VHA's leading role in the practice and the science of implementation. As mentioned by Fihn, one of the most important and innovative partnering efforts within VHA is the Quality Enhancement Research Initiative (QUERI), a program jointly sponsored by the Office of Research and Development and the Office of Quality and Performance, to focus attention on 9 of the most common, highest burden, and highest cost diseases treated within VHA. Veterans Health Administration Research has funded other solicitations and programs to promote and accelerate uptake of research findings and their systematic incorporation into clinical practice. Other research funding agencies are also

Address correspondence and requests for reprints to Dr. Kiefe: Birmingham VA Medical Center and the Division of Preventive Medicine, Department of Medicine, University of Alabama at Birmingham, Birmingham, AL (e-mail ckiefe@mail.dopm.uab.edu). grappling with these issues. The Agency for Healthcare Research and Quality (AHRQ) and the NIH have funded initiatives to promote the uptake of research or evidence based findings into clinical practice. Health systems in other countries such as Canada and the United Kingdom are examining the challenges of implementing research evidence into clinical practice.

Despite all these initiatives and the ground swell of interest and effort that surrounds these endeavors, there is still a profound sense among clinicians and quality of care researchers that we are only beginning dimly to perceive the shape of the path that we are on. Our knowledge base for implementation still has tremendous gaps on which the peer-reviewed literature is essentially silent (e.g., the importance of social networks in implementation work). Even in a system as integrated, technologically advanced, and committed to high-quality care as VHA, we find gaps in performance in some key areas. Veterans Health Administration has come a long way from its past, and it still has a long way to go.

The purpose of the Implementation SOTA was to assess and define the current state of knowledge about how to rapidly implement scientific evidence into health care, including evidence derived from research funded by VHA (http://www.va. gov/resdev) and others. Four workgroups to address current knowledge and define what knowledge is needed for the future were constituted for the SOTA. The topics for the workgroups were identified by posing questions to be addressed by the commissioned papers and discussed by the workgroups during the SOTA. These questions were:

1. What are the attributes of an ideal integrated informatics system that supports implementation of evidence?

2. How does evidence inform what an organization and its providers do?

3. What is the role of incentives in promoting implementation of best practices and organizational change?

4. How does research need to be reorganized to foster organizational and practice change?

\section{RECOMMENDATIONS FROM THE IMPLEMENTATION SOTA}

We now describe some of the key SOTA recommendations for a health care system like VHA and their implications. We have organized these into categories focusing on (1) dissemination of the evidence, (2) cost of "business as usual," (3) implementation research and diagnosis of performance gaps, and (4) competing demands.

\section{Dissemination of the Evidence}

If a specific practice change is sought, one clear imperative is to fully describe the evidence supporting the practice change, disseminating the foundations for the evidence to those expected to make changes, and using dissemination methods that are effective and will reach the targeted audience. ${ }^{3-7}$ This 
audience includes not only front-line providers, but also patients, front-line managers, and managers at all levels of the organization. This latter requirement flows from the need to enlist management in supporting the kind of organizational change that is often needed to support practice change, ${ }^{8-12}$ and also from the realization that sharing of knowledge between managers and clinicians is essential to reduce the transaction costs of implementing new evidence. However, the type of information disseminated must be tailored to the audience. Front-line providers will need information that allows them to take specific clinical action on the evidence. Patients need to understand the value of a practice change to their health and the effect a new treatment may have on their lives. Managers require information about the evidence, in a relatively short format, together with information about costs and resource requirements for implementation. All participants should have the opportunity to participate in decision making about how a change should be implemented in the local context-the specific clinic, hospital, or health care organization.

\section{The Cost of "Business as Usual"}

The need for this kind of transparent interaction and discussion about change is driven by a clear message from conference participants that "business as usual" in health care organizations creates transaction costs for any attempt to implement evidence into practice. "Business as usual" includes hierarchical structures, disciplinary silos, and what are often highly bureaucratized business processes. ${ }^{13}$ The transaction costs consist of extensive time and energy resources, making it very difficult for organizations to implement change rapidly, even when all parties nominally agree that a change is beneficial and desired. When there is even minor disagreement about evidence, the transaction costs of implementing change can overwhelm the change effort. An example of this situation is in efforts by the Ischemic Heart Disease QUERI to ensure adequate treatment of hyperlipidemia to prevent recurrent adverse cardiac events (heart attacks, unstable angina, and death). Even though there is essentially no disagreement among participants in VHA about the importance and benefit to patients' health of treating hyperlipidemia, there are minor disagreements about goals or targets of treatment. ${ }^{14}$ These minor disagreements have, at times, taken so much of the time and energy of participants in implementing evidence-based treatment that the implementation effort has stalled out. ${ }^{15}$

\section{Implementation Research and Diagnosis of Performance Gaps}

Another critical element in implementing evidence is careful diagnosis of the gap(s) in performance as part of planning for implementing practice change. One approach to diagnosing performance gaps is described by Kochevar. ${ }^{16}$ It involves process mapping, assessing organizational context and readiness to change, and other key features, and may be very difficult to accomplish using traditional models of investigator-initiated research. Indeed, research into the science of implementation, rather than research to generate best practices or evidence regarding optimal treatment modalities, is needed to enlarge our knowledge base. In implementation research, the traditional model of an investigator who is either completely, or mostly, external to the system of care being targeted, making decisions about how best to implement an evidence-based practice may not allow sufficient diagnosis unless there is explicit funding for the diagnostic step. The culture of health care organizations may have an effect on tolerance for what may be perceived as a relatively long diagnosis period, and managers or decision makers may expect more rapid action than may be possible. The duration of the diagnosis period is probably in proportion to the complexity of the system change required to implement the desired practice change. Relatively straightforward changes, such as switching from calcium channel blockers to thiazide diuretics for control of high blood pressure, may not require much diagnosis, although this example points out the need to assess the reasons why practice is not optimal initially. Even in a relatively straightforward example like this, the need to assess barriers and facilitators as part of the planning process is critical. Once a problem is diagnosed, targeting interventions through use of appropriate theory, linking tools to strategies, should improve the efficiency and effectiveness of the interventions. ${ }^{17}$ Given the range of disease entities, and the limited resources available, health care systems need to choose wisely in deploying their resources on specific system change efforts.

Another important facet of diagnosis is the assessment of performance gaps not just at the micro-level, in the microsystems where teams deliver care, but also at higher levels in the organization. The 2004 to 2005 influenza vaccine experience provides an example of the importance of assessing multiple levels. The Spinal Cord Injury QUERI has had significant success in improving influenza vaccination rates among VA patients with spinal cord injury. ${ }^{18,19}$ However, in the 2004 to 2005 influenza season, macro-level issues including the loss of 1 of only 2 national suppliers of vaccine provided a major challenge to adequate vaccine coverage beyond the micro-system level. The problem of inadequate supply required national intervention. It also raised multiple issues at lower levels, including appropriate assessment of who should receive limited supplies of vaccine, how that assessment should be made, and ensuring that some kind of priority system was put in place to ensure that those most at risk received highest priority for vaccination. In the past, the challenge had usually been to get providers to appropriately assess risk and administer vaccine to patients who may not appear to them to fit the risk profiles they are accustomed to using. In a period of global shortage, however, the issue became one of appropriate prioritization within risk populations. In this instance, it became necessary for providers to ensure that patients with spinal cord injury who were under 65 took priority over patients who were over 65 without chronic illness (a traditional risk group). This required system revamping in terms of patient notification, and education, to inform patients about their level of risk.

A critical issue, on which there is essentially no evidence and little likelihood of acquiring strong evidence, is whether a major overhaul of a system such as a large, integrated health care system is more efficient and effective than incremental change. There are examples of major system change as an effective mechanism for implementing system improvements and evidence-based care, notably in the VHA. ${ }^{20-22}$ Veterans Health Administration is an example of a system that has undergone major reforms, leading to some significant improvements in the quality of care delivered. ${ }^{23}$ However, this is only 1 health care system, and it is improbable that a randomized 
trial will ever be conducted at the system level to test the hypothesis that major overhaul is more effective and/or efficient than incremental change. By contrast, health care systems in Canada and the Netherlands, as well as other countries, have used more incremental processes to achieve gains in quality of care and improvements in patient safety. Major system change requires significant effort from the top of the system, while incremental change, while still requiring commitment by senior leadership, can flow from the top, middle, and bottom as sites of change initiation. The concept of the learning organization, ${ }^{24-28}$ applied to health care systems and organizations, suggests a more incremental approach, but not a haphazard one. Careful deployment of resources through diagnosis, planning, and learning-oriented implementation is one way to create systematic change without requiring major overhaul.

\section{Competing Demands}

One of the major complications in implementing evidencebased care is in balancing the demands of system change for quality improvement against all the other imperatives faced by a health care system. While a publicly funded health care system such as VHA faces different pressures from a nongovernmental system, either nonprofit or for profit, there are still resource limitations. Managing a large, integrated health care system requires continual response to ongoing pressures and demands, in both the private and public sector. While pressures related to managing public perception, in the case of VHA, or retaining (or increasing) market share (in the case of a privately operated health care system) may consume the attention of senior managers, it is essential that senior leadership support system changes required for implementing best practices. This is in part because messages from senior leadership carry significant weight, even among front-line providers who may not know the names of senior leaders in large organizations. The mandates, directives, and policy decisions promulgated from the highest levels of the organization do permeate the organization, especially if they are linked to performance measures that are in turn linked to performance assessment. Even when there is little financial risk to managers, public reporting of performance is a powerful mechanism for shifting behavior. If it is used in ways that do not appear to have coherence or evidence of strategic thinking, public reporting of performance can have perverse incentives, driving behavior in ways that do not ultimately support the implementation of best practices. ${ }^{29}$ In addition, performance measurement and public reporting is a tool that can lose effectiveness over time. Even with continuous change in the measures being measured and reported, particularly if many different performance measures are used, the impact of measurement and public reporting can blunt over time. Strategic deployment of this tool, as well as others, is essential to maintain its effectiveness. Beyond performance measurement, achieving leadership buy-in is required for any systematic efforts to implement change. Leaders can both lead by example, and facilitate processes for implementing change and achieving buy-in from other people in the organization, including providers and ancillary staff. Leadership buy-in and visible support for a change effort may be a necessary, but seldom sufficient, condition for achieving desired change.

\section{SUMMARY OF SOTA FINDINGS}

Over the course of the conference, and through the papers commissioned for it and included in this issue, several themes emerged. Again and again, conference participants were faced with the magnitude of our knowledge gaps in implementation science and the lack of evidence on how to implement evidence. Nonetheless, some consensus emerged relating to attributes of health care systems and organizations able to respond quickly to changes to promote evidence-based practice.

These include:

- flexibility,

- rapid uptake and testing of newly emerging evidence,

- leadership aligned to promoting effective system change through evidence-based management,

- formal leadership committed to supporting informal and emergent leaders supporting desired change,

- information systems aligned with implementation of evidence-based practice,

- reward and performance measurement and reporting systems aligned with implementation of evidence-based practice,

- ongoing commitment to research and creation of the evidence basis.

Achieving the ideal is a complex task that will take time and effort by participants at all levels of the organization, but efforts over time to effect these changes are likely to be beneficial. Approaches to instituting rapid-cycle testing of new interventions, coupled with systematic feedback and organizational learning in a nonpunitive climate, may facilitate larger system changes, as the effect of smaller successes and lessons learned fuel new willingness to attempt system change.

\section{AFTERWORD}

The Implementation SOTA generated an atmosphere of excitement, a sense of empowerment, a vision that, finally, in Goethe's words from 2 centuries ago, researchers are recognizing that "knowing is not enough, we must apply," and health care leaders are realizing that "willing is not enough, we must do." This issue of the Journal summarizes some of the clearest thinking in this new health care-related area of discovery, Implementation Science. And yet the scarcity of data in this Journal issue is striking. What does this mean? Why could the remarkable thought pieces produced by this conference, which was all about empirical evidence and how to use it for the benefit of our patients and populations, not be more data driven? This apparent paradox speaks volumes about both the infancy and the urgency of Implementation Science.

Almost exactly 1 year after the Implementation SOTA, another invitational conference took place in Washington, DC. This time, it was convened not by VHA alone, but also by AHRQ, NIH, CDC, and the Robert Wood Johnson Foundation. This conference's theme was "Expanding Research and Evaluation Designs to Improve the Science Base for Health Care and Public Health Quality Improvement." Representatives from governmental and nongovernmental health care payer groups participated actively. With many participants in common to the 2 meetings, the themes were quite similar, but new and more data were presented. It was almost as if the Imple- 
mentation research community itself were engaging in repeated cycles of "Plan, Do, Study, Act." We hope that a multitude of new cycles will emerge, not just as invitational, perforce elite, conferences, but rather as ever growing waves of expanding knowledge coupled with actions, to transform our remarkable scientific gains into the improved health of our patients and populations.-Catarina I. Kiefe ${ }^{1}$, MD, PhD, Anne Sales, ${ }^{2}$ MSN, PhD, RN. ${ }^{1}$ Birmingham VA Medical Center and the Division of Preventive Medicine, Department of Medicine, University of Alabama at Birmingham, Birmingham, AL, USA; ${ }^{2}$ VA Puget Sound Health Care System and the Department of Health Services, University of Washington, Seattle, WA, USA.

\section{REFERENCES}

1. Institute of Medicine, Committee on the Quality of Health Care in America. Crossing the Quality Chasm. A New Health System for the 21 st Century. Washington, DC: National Academy Press; 2001.

2. Balas E, Boren S. Managing clinical knowledge for health care improvement. Yearbook of Medical Informatics. 2000;65-71.

3. Kitson A, Harvey G, McCormack B. Enabling the implementation of evidence based practice: a conceptual framework. Qual Health Care. 1998; 7:149-58.

4. Rycroft-Malone J, Harvey G, Kitson A, McCormack B, Seers K, Titchen A. Getting evidence into practice: ingredients for change. Nurs Stand. 2002;16:38-43.

5. Rycroft-Malone J, Kitson A, Harvey G, et al. Ingredients for change: revisiting a conceptual framework. Qual Saf Health Care. 2002;11:174-80.

6. Rycroft-Malone J, Seers K, Titchen A, Harvey G, Kitson A, McCormack B. What counts as evidence in evidence-based practice? J Adv Nurs. 2004;47:81-90.

7. Grimshaw JM, Thomas RE, MacLennan G, et al. Effectiveness and efficiency of guideline dissemination and implementation strategies. Health Technol Assess. 2004;8:iii-iv, 1-72.

8. Ferlie E. Large-scale organizational and managerial change in health care: a review of the literature. J Health Serv Res Policy. 1997;2:180-9.

9. Ferlie E, Fitzgerald L, Wood M. Getting evidence into clinical practice: an organisational behaviour perspective. J Health Serv Res Policy. 2000; 5:96-102.

10. Grimshaw J, Youngs H. Towards better practice management: a national survey of Scottish general practice management. J Manag Med. 1994;8:56-64.

11. Grol R, Baker R, Moss F. Quality improvement research: understanding the science of change in health care. Qual Saf Health Care. 2002;11: 110-1.
12. Heinrich CJ, Lynn LE Jr. Improving the organization, management, and outcomes of substance abuse treatment programs. Am J Drug Alcohol Abuse. 2002;28:601-22.

13. Ferlie EB, Shortell SM. Improving the quality of health care in the United Kingdom and the United States: a framework for change. Milbank $Q$. 2001;79:281-315.

14. Wilt TJ, Bloomfield HE, MacDonald R, et al. Effectiveness of statin therapy in adults with coronary heart disease. Arch Intern Med. 2004; 164:1427-36.

15. Hagedorn H, Hogan M, Smith JL, et al. Lessons learned about implementing research evidence into clinical practice: experiments from VA QUER1. J Gen Intern Med. 2006;21(suppl 2):S2 1-S29.

16. Kochevar LK, Yano EM. Understanding health care organization needs and context: beyond performance gaps. J Gen Intern Med 2006;21(suppl 2):S25-S29.

17. Sales A, Smith J, Curran G, Kochevar L. Models, Strategies and tools: theory in implementing evidence-based findings into health care practice. J Gen Intern Med. 2006;21(suppl 2):S43-S49.

18. Legro M. Lessons learned while working toward a new health system for the 21 st century. SCI Nurs. 2004;21:124-6.

19. Weaver FM, Goldstein B, Evans CT, et al. Influenza vaccination among veterans with spinal cord injury: part 2 . Increasing vaccination rates. $J$ Spinal Cord Med. 2003;26:210-8.

20. Kizer KW. The "new VA": a national laboratory for health care quality management. Am J Med Qual. 1999;14:3-20.

21. Kizer KW, Demakis JG, Feussner JR. Reinventing VA health care: systematizing quality improvement and quality innovation. Med Care. 2000;38(suppl 1):I6-7.

22. Kizer KW, Fonseca ML, Long LM. The veterans healthcare system: preparing for the twenty-first century. Hosp Health Serv Adm. 1997;42: 283-98.

23. Jha AK, Perlin JB, Kizer KW, Dudley RA. Effect of the transformation of the veterans affairs health care system on the quality of care. N Engl J Med. 2003;348:2218-27.

24. Ferlie E, McKee L. Planning for alternative futures in the NHS. Health Serv Manage Res. 1988;1:4-18.

25. Grol R. Changing physicians' competence and performance: finding the balance between the individual and the organization. J Contin Educ Health Prof. 2002;22:244-51.

26. Lomas J. Diffusion, dissemination, and implementation: who should do what? Ann NY Acad Sci. 1993;703:226-35; discussion, 227-235.

27. Mittman BS. Creating the evidence base for quality improvement collaboratives. Ann Intern Med. 2004;140:897-901.

28. Ockene JK, Zapka JG. Provider education to promote implementation of clinical practice guidelines. Chest. 2000;118(suppl):33S-39S.

29. Christianson JB, Knutson DJ, Mazze RS. Physician pay-for-performance: implementation and research issues. J Gen Intern Med. 2006; 21(suppl 2):S9-S13. 